\title{
Conceptual model of Logistics Vocational Education in the digital economy
}

\author{
Vladimir Scherbakov \\ Department of Logistics and Supply \\ Chain Managemen \\ St. Petersburg State University of \\ Economics \\ St. Petersburg, Russian Federation \\ shefainn@yandex.ru
}

\author{
Galina Silkina \\ Graduate School of Business and \\ Management \\ Peter the Great St.Petersburg \\ Polytechnic University \\ St. Petersburg, Russian Federation \\ galina.silkina@gmail.com
}

Abstract - A precedent has been created to substantiate a scientific and methodological approach to the professional training of logisticians in the Russian higher education system which is being reformed now. The principal characteristics of the approach are determined: preactivity, personal orientation, continuity of education, competency-based development of students defining imperatives of adaptive management of the educational process for training taking into account the current trends in the development of logistics in the context of the digital economy.

It has been developed the scientific concept on logistics as a digital profession and a logistician as a profession owner - a person in the digital society with an active life position and mentality as a network logistics professional who implements the principles of self-organization, self-education and selfrealization on the basis of the acquisition /professional development and development of professional competencies.

A conceptual model of professional educational level of logisticians is proposed, which implements the imperatives for interaction of the labor market, higher education system and students in total of the concepts and the relationships between them that determine the formulation of the main professional educational programs. The key concepts of the educational model are substantively disclosed: a job profile diagram - a tool for formation of the universal model of competencies in the management of the educational process; a career path is a tool for formation of an individual model of competencies in employment and career management; individual educational trajectory is a tool of personality-centered education. The requirements for the logistician's professional competencies and the over-professional competencies that shape his/her professional mentality are outlined.

Recommendations for the harmonization of job profile diagrams and career paths in the conceptual educational model of the logistician using the tools of strategic management management strategies and career self-management are presented.

The trends of the further study development in ensuring the properties of "smart", self-organizing and self-optimizing model are determined when it includes professional levels adjacent to the higher education system - secondary vocational and supplementary vocational education.

Keywords - logistician educational model, job profile diagram, career paths, individual educational trajectory

\section{INTRODUCTION}

The problem under consideration is invariant in its formulation - the professional adaptation to the economic situation where his/her potential will be in demand. This is an economic problem, since it regards the training cost training and retraining during the life cycle of his/her labor activity [1]. From the point of view of the application of activity, this is a problem that is equally relevant for all areas of economic activity, but which requires to take into account professional specifics in its decision. In this statement, the applied context of the problem is associated with the logistics - a wide area of professional activity serving the needs of the production and commodity circulation sectors in the organization of flow processes.

The assessment of the current situation in the Russian economy and its development prospects leads to the conclusion that a modern approach to the professional training of logisticians is formed in a three-dimensional space of transformations. And the first of them is the reform of the higher professional education system in Russia correlated with the education reform in general. Reform conversions are associated with the creation of multilevel system of continuing education, which is consistent with the system of secondary vocational education and adjusted, in contrast to the previously existing system, not to the learning process, but to the result - achievement of competence with the dynamic knowledge base.

The second dimension is the total progresses in the economy associated with the transition to the fifth technological mode, the essence of which is determined by the convergence of sciences and technologies with an emphasis on computer science and informatization, as well as the beginning of the fourth industrial revolution with its key idea of customer focus in solving all economic challenges $[2,3]$. The peculiarity is due to the simultaneous deployment of transformations, which increases the requirements for predictive analytics in assessing the expected results of the development of the economic situation in the future [4,5], taking into account the fact that its modern dynamics are determined by the processes of total digital transformation affecting not only the economy, but also society as a whole $[6,7,8]$.

The third dimension is the beginning of a new stage in the evolutionary development of the logistics itself as a convergent science and divergent practice in the context of digitalization. The question is the transition from supply chain management to network logistics [9], where the business model and business architecture become the main objects of logistical effect, and the scope of logistic activity application in managing business processes extends to the 
boundaries of the goods life cycle, including its development and commercialization.

\section{MATERIALS AND METHODS}

An interdisciplinary research resource based on the methods of edukology is used in the development of a model of professional educational training for a logistician. The applied nature and adaptability of the model as a tool for managing education/ training is provided by meaningful interpretation and predictive analytics of the economic situation dynamics with the use of research methods applied in the logistics combined with general scientific methods of economic research - observation and collection of facts, scientific abstraction, simulation, graphical interpretation, system analysis and design.

\section{RESULTS}

In the light of these features, the main difference between the modern approaches to the training of logisticians is that, while retaining the features of adaptive education management, it must take into account the high speed of transformations. And this means that in the practice of its application it is necessary to rely on advancing, maximally combining reactivity with personal orientation in ensuring the continuous competence development of students.

The hypothesis developed in this way aims the study at the formation of the logistician educational model. A modern logistician is a person belonging to the digital society with an active life position and mentality as a network logistics professional who implements the principles of self-organization, self-education and selfrealization on the basis of the acquisition /improvement of qualification and development of professional competencies.

The justification of the professional educational training model for a logistician follows the logic correlated with the requirements of the current National Qualifications System and takes into account promising findings in the field of development of competencies of the Agency for Strategic Initiatives (ASI), including the up-to-date Roadmap project "Creation of the National Competency and Qualifications System" [10]. According to the developers, the National system of competencies and qualifications is:

- a set of interconnected elements necessary in the field of labor and professional education, which ensures the process for modernization of national and regional economies;

- a totality of mechanisms for legal and institutional regulation of the demand for qualifications of workers from supply market and qualifications demand from the education and training system;

- a system that describes and forms the relationship of professional, business, and government in creating, developing, accumulating, reproducing, evaluating, and protecting competencies nationwide to increase the country global competitiveness.

In accordance with the status and purpose, the National system of competencies and qualifications appears to consist of:
- the goals of professional education balanced between the state, business and citizen;

- educational programs for training of skilled workers;

- informatively flexible educational content that changes as per the economy needs;

- mechanisms of close interaction in training of professionals between the state and business;

- incentives for joint funding of vocational training from the business and the state;

- professional standards;

- professional communities that form and structure the vocational education system;

- systems of independent assessment of qualifications.

The educational model principally built on the basis of system requirements appeals to the characteristics of mentality of a person as a social and cultural category. Moreover, the cyclical nature of the model action is ensured by the development of professional mentality, which shall become a product of the vocational education system [11].

\section{DISCUSSION}

The Russian education reform fundamentally changes the attitude of all interested parties: person (individual), educational organization, business, as well as the state from which this reform is originated. In reality, a transition is made from mass education for all to individual education for everyone. The attention is shifted to the person for whom education, or the active realization of an interest in learning, shall become a conscious part of life as a whole. A sign of a new reality is the fact that along with specialized organizations providing services in the system of higher professional education (in connection with the professional training of qualified and highly qualified logisticians we are talking specifically about it), service organizations appear including virtual ones which are serving users in the mode "24/360 " education" - "continuously and everywhere" in terms of activating the educational services supply and demand formation. Their exact place of presence in the model of professional educational training of a logistician is not defined, but the function is indicated - the creation of informational, marketing environment for the educational services market. A prime example is the organization within the framework of the National Competencies and Qualifications System of automated educational RPA software "YaPROFESSIONAL.RF" [12]. The service solves the problem of employment, quality hiring and audit of the competencies of employed personnel; it is a career planning tool based on created job profile diagrams, competency models and personal preferences, which uses professional testing methods and proposes the acquisition of missing knowledge in educational institutions of the country. It is easy to assume that such services can find demand among a wider audience than the working population, and the providing organizations can acquire a consulting profile.

However, the visible possibilities remain outside the scope of the proposed fundamental solutions. The conceptual educational model of the logistician professional education is built around the classical participants of the educational process - the labor market (the state and 
business represented by employers), education (institutions of the higher education system), students (individuals). The participation lines of employers and individuals form demand, educational institutions inside - the supply of educational services (fig. 1).

On following the ideas that the conceptual model is built to form the conceptual structure of the object, uses various concepts and relationships between them, it will be logical to consider tools of professional educational training as the reference points of the model, which are: job profile diagram, career path and an individual educational trajectory.

The job profile diagram in the model is a tool for formation of a universal model of competencies in the educational process management. The document is completed based on the results of job study, job analysis, specifically educationally oriented, proactive job analysis, and this title reflects both the study goal and document purpose, which determines its content. Substantially - this is a profession characteristic represented by a description of the professional activity specifics through the system of profession requirements specified for the person, his/her characteristics, including personal properties, features of thought processes, as well as the necessary knowledge, skills that he/she has to successfully engage this activity.

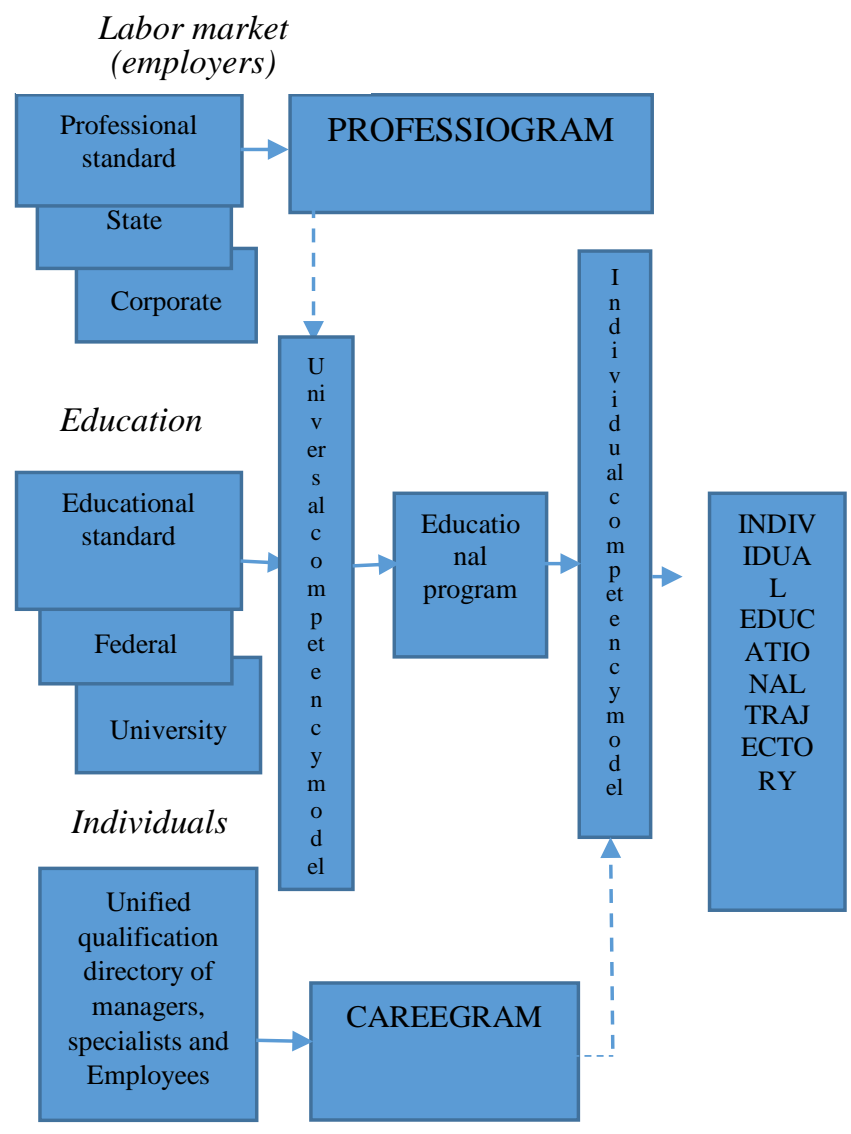

Fig. 1. The conceptual model of educational training in the system of higher professional education (conceptual diagram)
In terms of meaning, the basis for building job profile diagrams shall be (if any) professional standards, including state and corporate ones. In terms of practical implementation of the model, the complexity is due to the lack of the necessary set of professional standards in the field of logistics. Among the first professional standards of the National Qualifications System to be included in the National Register are: Professional standard 40.049 - the standard of transport logistics specialist approved by order No. 616n of the Ministry of Labor of Russia dated 09.08.2014 (the type of professional activity is logistics activity in the transportation of goods in the supply chain); Professional standard 40.084 - Specialist in arrangement of engineering companies supply chains approved by order No. $1142 n$ of the Ministry of Labor of Russia dated 12.25.2014 (the type of professional activity is organization of supply chains of engineering companies; Professional standard 40.135 - Specialist in logistics in the field of waste handling approved by order No. $1147 \mathrm{n}$ of the Ministry of Labor of Russia dated 12.24.2015 (the type of professional activity is organization and conduct of logistics operations in the field of waste handling), etc.

However, the principle of education preactivity requires that along with the educationally oriented job analysis to use the possibilities of prospective job analysis, the purpose of which is to issue the recommendations for improving professional activities, designing professional progress and career. Along with the general characteristic, scope and content of the legal field (taking into account the development forecasts), requirements for professional education, training and advanced training, professional mobility, such a job analysis assesses the profession prospects and jointly the required characteristics of the professional and psychological personal potential are recorded personality, professional activity, professional selfimprovement and career are recorded.

The results of special studies, such as the research project "Foresight of Competences 2030" of the Moscow School of Management SKOLKOVO implemented jointly with the Agency for Strategic Initiatives and presented to the public in the Atlas of New Professions 2.0, can provide certain assistance. The profession of a logistician has been developed in relation to the transport industry: for students training in the system of higher professional education, the Atlas has determined the following types of professional employment [13, p. 98, 101]:

- cross-logistics operator - a specialist whose competence includes the selection of the optimal method for delivering goods and moving people using various types of transport, monitoring and correction of flows through the traffic network, monitoring the passing ability of transport hubs, redistributing the flows of traffic networks;

- designer of intermodal transport hubs - a developer of distribution systems for cargo and passenger flows, whose competence includes substantiating the transport capability, wearing qualities calculation, development potential assessment;

- architect of intelligent control systems - a designer of automated transport control systems including unmanned 
ones, traffic flow control systems, control of intelligent complex traffic control systems.

However, the selectivity of the research approach and as a consequence the fragmentation of prognostic-analytical information does not allow large-scale deployment of proactive work in setting the main professional educational programs [14-19]. In any case, it is to the extent that modern trends in the digitalization of logistics suggest. Due to the development of network forms of logistics organization in the context of the digital economy generation, they entail a number of significant organizational and economic transformations that affect the grounds of logistics activity and, therefore, the requirements for the logistician profession. The respective progress is expressed by a change in priorities in logistics management, namely: [20, p. 198206]:

transition from mass customer service to the customer focus of the logistics business;

from the efficiency of logistics business processes to the effectiveness of customer service; joint use of logistics potential; stimulation of lean consumption of logistics services based on the formation and the use of consumer experience;

from the activities of $3 \mathrm{PL}$ and $4 \mathrm{~L}$ providers to the activities of 5PL providers of hardware and software logistics services;

from integration of front and back offices (contact centers), functioning of coordination logistics centers to virtual system integration, logistics information and technology software, ensuring logistics customer service omnichannel;

from hypertrophy of the non-disclosure mode of business (commercial) information to informational hypertransparency of the logistics business and logistics processes with a full guarantee of confidentiality and information security in general;

from local logistics management systems to software and ecosystem integration.

Against the background of such progresses, the substantiation of the characteristics of the professional and psychological potential of a person engaged in logistics, his/her professional activity becomes an independent research task going back to the formation of professional logistician and professional mentality as a whole. Once again, the results of studies in terms of the type presented at the World Economic Forum (Davos, 2016) under the topic of "The Fourth Industrial Revolution" can be helpful. In the dynamics, the report "The Future of Jobs" determines the rank sequence of skills and experience that form the socalled super-professional competencies (Table I). In terms of the Federal State Educational Standards (FSES) of higher education, these are general cultural or universal competencies.

TABLE I. 10 ESSENTIAL SKILLS REQUIRED FOR PROSPERITY [20]

\begin{tabular}{|c|c|}
\hline 2015 & 2020 \\
\hline Solving of complex problems & Solving of complex problems \\
\hline $\begin{array}{c}\text { Ability to coordinate actions } \\
\text { with other employees }\end{array}$ & Critical thinking \\
\hline People management & Creativity \\
\hline Critical thinking & People management \\
\hline
\end{tabular}

\begin{tabular}{|c|c|}
\hline Ability to negotiate & $\begin{array}{c}\text { Ability to coordinate actions } \\
\text { with other employees }\end{array}$ \\
\hline Quality control & Emotional intelligence \\
\hline Service orientation & $\begin{array}{c}\text { Ability to mind and make } \\
\text { decisions }\end{array}$ \\
\hline $\begin{array}{c}\text { Ability to mind and make } \\
\text { decisions }\end{array}$ & Service orientation \\
\hline Listening skills & Ability to negotiate \\
\hline Creativity & Cognitive flexibility \\
\hline
\end{tabular}

Accordant and identically in the content, the Atlas of new professions 2.0 defines "over-professional skills" as the most important for professionals of the future [13, p. 26-36]:

- systemic thinking (the ability to define complex systems and work with them, including system engineering);

- inter-industry communication skills (understanding of technologies, processes and market situation in various related and non-related industries);

- project management (ability to manage projects and processes);

- lean manufacturing (management of the production process based on a constant desire to eliminate all types of losses, which involves each employee in the process of business optimization and customer orientation maximization);

$$
\text { programming/robotics/artificial intelligence }
$$

(programming of IT solutions/management of complex automated systems/work with artificial intelligence);

- customer focus (ability to work with consumer requests);

- multilanguage and multiculturalism (fluency in English and knowledge of the second language, understanding of the national and cultural context of partner countries, understanding of the specifics of work in industries of other countries);

- work with people (ability to work with teams, groups and individuals);

- work in conditions of uncertainty (the ability to be quick in decisions, respond to changing working conditions, the ability to allocate resources and manage your time);

- environmental thinking.

The second related concept of the logistic conceptual educational model is a career path. A career path is a tool for formation of an individual model of competencies in employment and career management. The career path compiled by a person regarding him-/her on the initiative basis is a personal plan for progress, for example, in terms of senior management positions and other key positions of the company. When the company plans, the career path becomes a kind of administrative contract concluded between the employer and employee on the specialist prospects in the company; its information content is achieved thanks to the adopted formalization. The contents of the employee's career path include: his/her personal data; occupied (starting) position; work experience in the position held; personal career orientations of the employee; progress opportunities in the current position; employee history in the company; training information; certification results; the knowledge, skills and abilities necessary to occupy the higher position, type and methods of training that shall be completed to enter a new position; a level of personnel reserve to which the employee is assigned; availability of vacancies in the company. 
Unlike a job profile description, descriptive document, the career path is presented, inter alia, in a graphic form that clearly reflects changes in the career (and not only progress) including options of the path meeting the psychological characteristics of the person: "springboard", "ladder", "snake", "crossroads".

And finally, the individual educational trajectory as the final stage in the triad of related concepts that determine the conceptual model output. The individual educational trajectory is a tool of personality-oriented education. It is a goal-oriented educational program that embodies the choice in implementation of the educational standard (federal or university) and has a complex structure. The individual trajectory includes the following components:

- target - involves setting the goals and determining the lines of activities for education, which are formulated on the basis of the educational standard,taking into account the motives and needs of students;

- substantial - reflects the content of education implemented within the framework of the specific educational program;

- technological - provides for the use of technologies, methods, techniques, training and education systems;

- diagnostic - reveals the system of diagnostic support;

- organizational and pedagogical - determines the conditions of implementation, student characteristics (age, level of readiness for assimilation, educational needs), to which the educational program is addressed; forms of achievements certification, etc.;

- effective - contains the description of the expected implementation results.

The individual educational trajectory built as a singlelevel target program (for example, a bachelor's degree) can be developed in higher level programs (master's degree, postgraduate study) - the formulation and solution of such a problem is considered as an element of the strategic approach related to the harmonization of job profile description and career paths. A tool of individual participation in the formation and prolongation of the individual educational trajectory can be his/her career selfmanagement strategy; employer engagement - staff career management strategy.

If the student is planing and/or has guarantees for employment in a particular company or is already employed, is in the employ of the company, then his/her personal, individual career progress strategy will gain a real opportunity for coordination with the company's career management strategy, and more durable basis for planning your own educational projects as a vector of educational trajectories. The harmonization is headed the adaptation of individual ideas on career advancement to the company capabilities in the field of professional and job transfers and it is achieved by harmonizing personal career challenges in the field of the organizational needs of qualified personnel.

However, an additional difficulty is found in the fact that career management practice has not acquired the necessary scale in Russia yet. With the obvious advantages of the method for building the career paths and their combination with job profile diagrams (motivates to achieve results, stimulates professional and personal advancement, ensures transparency and fairness of the system of job transfers), it reveals a high complexity in mastering, the need for regular review of the hierarchical structure of the organization, the introduction of "status" positions etc. And therefore, building individual educational paths based on harmonization of career paths and job profile diagram so far remains more empirical task of finding solutions than the task of behavioral management in career management and self-government. The same can be referred to the implementation of individual education trajectories. The substantiation of the corresponding mechanisms leads to the design and targeted management of educational programs, including using resources of flexibility and adaptability of the block-modular program structure.

\section{CONCLUSIONS}

In order to ensure the transition from the conceptual model to the practice for the development of popular and improved educational projects, the further development of the studies is seen in making a "smart" model for the educational model of the logistician that is self-organizing and self-optimizing when implementing the potential of information and communication technologies and adequate innovative teaching methods. In this case, a separate aspect is the provision of a line of connection between higher professional education and secondary vocational education (at the entry), as well as with additional professional education (at the output), i.e. ensuring continuity - all this from the perspective of solving the problems of long-term hiring and strategic career management on the planning horizon, scale to the life cycle of a professionals labor activity.

\section{REFERENCES}

[1] Manyika J., Lund S., Chui M., Bughin J., Woetzel J., Batra P., Ko R., Sanghvi S. "Jobs lost, jobs gained: What the future of work will mean for jobs, skills, and wages". McKinsey Global Institute, 2017: [Electronic resource]. URL: https://www.mckinsey.com/featuredinsights/future-of-organizations-and-work/Jobs-lost-jobs-gainedwhat-the-future-of-work-will-mean-for-jobs-skills-and-wages. (accessed date is 29.10.2018).

[2] "Digital Planet 2017: How Competitiveness and Trust in Digital Economies Vary Across the World" in The Fletcher School of Law and Diplomacy, Tufts University: [Electronic resource]. URL: https://sites.tufts.edu/digitalplanet/files/2017/05/Digital_Planet_2017_ FINAL.pdf (Дата обращения: 29.10.2018).

[3] Schwab K., Davis N. "Shaping the Fourth Industrial Revolution". World Economic Forum, 2018.

[4] "Forecast of the scientific and technology development of Russia: 2030. Information and communication technologies"/Edited by L.M. Hochberg, I.R. Agamirzyan. M: Ministry of Education and Science of the Russian Federation, National Research University "Higher School of Economics", 2014.

[5] Bolsunovskaiya, M.V., Shirokova, S.V., Loginova, A.V. The system theory and system analysis applications in IT projects management: Development of hardware and software complex for predicting failures in data storage systems (2018) pp. 6298-6307.

[6] Semyachkov K. A. "Digital economy and its role in the management of modern socio-economic relations" in Modern management technologies: [Electronic resource]. URL:
a http://sovman.ru/article/8001. (accessed date is 29.10.2018).

[7] "Digital Economy: Global Trends and Practice of Russian Business" [Electronic resource]. URL http://www.vcpp.ru/media/1181/tsifrovaya-ekonomika-globalnyetrendy-i-praktika-rossiyskogo-biznesa.pdf. (accessed date is 07.07.2019). 
[8] Borremans, A.D., Zaychenko, I.M., Iliashenko, O.Yu. Digital economy. IT strategy of the company development (2018) 170 , 01034.

[9] "New Logistics Trend Radar 2018/19. Delivering Insights Today, Creating Value Tomorrow". [Electronic resource]. URL: https://www.logistics.dhl/. (Accessed date is 22.10.2018).

[10] "ASI projects in the field of competency development": [Electronic resource]. URL: http://unpo.tomsk.gov.ru/Files/e1073beb-845d$483 \mathrm{c}-\mathrm{af} 1 \mathrm{a}-$

70ef03a2ae3b/3.Томск.\%20Подходы\%20к\%20формир.\%20НСКК $\% 20$ АСИ.pdf. (Accessed date is 05.07.2019).

[11] Popova E.A. "The concept of professional mentality in the scientific literature" in Pedagogy and psychology of vocational education. 2010. No. 2, pp. 47-55.

[12] "YAPROFESSIONAL.RF": [Electronic resource]. URL: http://xn-80ajjnidcejma7a3k.xn--

p1ai/\%d1\%81\%d0\%b8\%d1\%81\%d1\%82\%d0\%b5\%d0\%bc\%d0\%b0$\%$ d1\%8f\%d0\%bf\%d1\%80\%d0\%be\%d1\%84\%d0\%b5\%d1\%81\%d1\% $81 \%$ d0\%b8\%d0\%be\%d0\%bd\%d0\%b0\%d0\%bb-

$\%$ d $1 \% 80 \%$ d $1 \% 84 / \%$ d $1 \% 81 \%$ d $1 \% 83 \%$ d $1 \% 82 \%$ d $1 \% 8 \mathrm{c}$

$\% \mathrm{~d} 0 \%$ bf\%d1\%80\%d0\%be\%d0\%b5\%d0\%ba\%d1\%82\%d0\%b0-

$\%$ d1\%8f\%d0\%bf\%d1\%80\%d0\%be\%d1\%84\%d0\%b5\%d1\%81\%d1\% $81 \% \mathrm{~d} 0 \%$ b8\%d0\%be\%d0\%bd\%d0\%b0\%d0\%bb-\%d1\%80\%d1\%84/ (Accessed date is 05.07.2019).

[13] “Atlas of New Professions 2.0"/Edited by Pavel Luksha. 2nd edition, Rev. and corr. M.: Olimp-Business Publishing House, 2016.
[14] "Main trend in Russian education is digitalization. 2017": [Electronic resource]. URL: http://www.ug.ru/article/1029. (Accessed date is 22.09.2018).

[15] Terelyansky P.V., Kuznetsov N.V., Ekimova K.V., Lukyanov S.A. "Education transformation in the digital era". In University Management: Practice and Analysis. 2018; 22(6). Pp 36-43.

[16] Shmelkova L.V. "Personnel for the digital economy: looking into the future" in supplementary vocational education in the country and the world. 2016. No. 8 (30), pp. 1-4.

[17] Kupriyanovsky V.P., Sukhomlin V.A., Dobrynin A.P., Raikov A.N., Shkurov F.V., Drozhzhinov V.I., Fedorova N.O., Namiot D.E. "Skills in the digital economy and the challenges of the education system" in International Journal of Open Information Technologies. 2017. No. 1, pp. 19-25.

[18] Ignatova N.Yu. "Education in the digital era". Nizhny Tagil: NTI (branch) of Ural Federal University, 2017.

[19] Kankovskaya, A., Kalinina, O., Ilin, I. Economics of transport and sustainable development: Problems of high education in Russia (2018) MATEC Web of Conferences, 239, 08008.

[20] Silkina G.Yu., Scherbakov V.V. "Current Trends in Logistics Digitalization.” St. Petersburg: POLITEKH-PRESS, 2019.

[21] Skinner C. "Digital Human". Marshall Cavendish International (Asia) Pte Ltd, 2018 